\title{
Outcome of grommet tube insertions among adult Nigerians with serous otitis media
}

\begin{abstract}
Dear Sir,
Otitis media with effusion (OME) is the presence of fluid in the middle ear without features of acute ear infection, due to Eustachian tube dysfunction, which could result in conductive hearing loss (CHL) ${ }^{[1,2]} \mathrm{It}$ is a childhood condition, rare among adults, ${ }^{\left[{ }^{[3]}\right.}$ and its presence is a pointer to a nasopharyngeal tumor until otherwise proven. ${ }^{[4]}$
\end{abstract}

Various studies on OME among children have been done worldwide, but with few reported among adults. ${ }^{[5]}$ Also few studies have commented on the efficacy of myringotomy and grommet tube insertions in the treatment of adults with OME, ${ }^{[6]}$ and this study aims to determine outcome of the later among adults in Ilorin, Nigeria.

This study was carried out between October 2005 and September 2007 at the ENT clinic of the University of Ilorin Teaching Hospital, Ilorin, Nigeria, on patients aged 18 years and above with diagnosis of OME based on history of CHL, ear blockage; otoscopic findings of dull tympanic membrane (TM), retraction pockets with loss of light reflex; Pure Tone Audiogram (PTA) findings of CHL and a type $B$ tympanogram (Jerger's classification). The indications for grommet tube insertions included failed medical treatment, retracted and glue-colored TM. Excluded were individuals with perforated TM and complicated OME

Aero Tymp PTFE/8' Armstrong Vinyl grommet tubes were inserted into the pars tensa of the TM under general anesthesia (GA) via face mask with inhalation agents. Magnification was aided by surgical loupe and operating headlamp.

All had posterior rhinoscopy and EUA of the nasopharynx to screen for nasopharyngeal tumors.

The outcomes studied were hearing thresholds, complications, time of extrusion of tube, preoperative and postoperative PTA at 500 to $2000 \mathrm{~Hz}$.

The follow-ups were done at 1, 2, 3 and 12 months after surgery. Data were entered into EPI-INFO and analyzed descriptively.
The procedure was performed on 15 patients. Their age range was 20 to 50 years (mean, 31.6 years). Among them, there were 5 males and 10 females, with a male-to-female ratio of 0.5:1.0.

The commonest age group was $21-40$ years $(60 \%)$, followed by $41-60$ years $(26.7 \%$ ) and less than 20 years (13.3\%). The hearing thresholds were the PTA averages over 500 to $2000 \mathrm{~Hz}$. The mean preoperative PTA was $30 \mathrm{db}$. All the ears maintained an improvement in the air-bone gap over the study period [Table 1], and none had lesions of the nasopharynx.

The procedure of grommet tube insertions is said to be the treatment of choice for uncomplicated OME extending beyond 3 months, as the tube is believed to replace the Eustachian tube function for a period of 6 to 9 months. ${ }^{[7]}$

Individuals with tube insertions were said to more likely have reduction of their air-bone gap (ABG) to within $20 \mathrm{db}$ at 1,3 and 9 months postoperatively. ${ }^{[8]}$ This is similar to findings in our study of gradual reduction from within a month after surgery up to a year afterwards. However, it is said that there is no beneficial effect after a year. ${ }^{[8]}$ This we could not conclude from this series as the follow-up was only for a year.

Long-term tubes are usually associated with crusting, granulation and infection. ${ }^{[6]}$ The only effects recorded in our study were crusting and otorrhea in 4 cases, all of which resolved with ear toileting and antibiotic therapy.

The finding of no lesion in the nasopharynx in our study is similar to findings in Zikk's series, in which

\begin{tabular}{|c|c|c|}
\hline & $\begin{array}{l}\text { Mean air-bone } \\
\text { gap (ABG) }\end{array}$ & $\begin{array}{c}\text { Range of } \\
\text { air-bone gap }\end{array}$ \\
\hline Preoperatively & 30 & $25-45$ \\
\hline $\begin{array}{l}1 \text { month } \\
\text { postoperatively }\end{array}$ & 25 & $25-38$ \\
\hline $\begin{array}{l}3 \text { months } \\
\text { postoperatively }\end{array}$ & 15 & $10-25$ \\
\hline $\begin{array}{l}6 \text { months to } 1 \text { year } \\
\text { postoperatively }\end{array}$ & 13 & $11-23$ \\
\hline
\end{tabular}


no nasopharyngeal tumor was identified in 12 cases with adult OME that were reviewed. ${ }^{\left[{ }^{[3}\right.}$ Postnasal space examination is further necessitated by the fact that nasopharyngeal tumor is common in the third and fifth decades of life, at which stage most of our patients were. Nasopharyngeal tumors have been known to present with otological features of OME, in addition to nasal, neuro-ophthalmic and neck symptoms.

Page $\mid 282$

Myringotomy and grommet tube insertions are useful in the treatment of adult-onset OME, and OME being a pointer to nasopharyngeal tumor must be borne in mind in the evaluation of these patients.

\section{B. S. Alabi, B. O. Bolaji ${ }^{1}$, S. Segun-Busari, S. K. Aremu, O. A. Afolabi}

Departments of Otolaryngology and ${ }^{1}$ Anaesthesia, University of Ilorin Teaching Hospital, Ilorin, Nigeria

Address for correspondence: Dr. B. S. Alabi, Department of Otolaryngology, College of Medicine, University of
Ilorin Teaching Hospital, P.O. Box 4210, llorin, Nigeria. E-mail: Alabibis@yahoo.com

DOI: $10.4103 / 1596-3519.59586$

\section{References}

1. Shekelle P, Takata G, Chan LS. Diagnosis, natural history, and late effects of otitis media with effusion. Evidence report/technology assessment No. 55. AHRQ Publication No. 03-E023. Rockville, MD: Agency for Healthcare Research and Quality; 2003.

2. Tos M. Epidemiology and natural history of secretory otitis. Am J Otol1984;5:459-62.

3. Paparella MM.The middle ear effusions. In otolaryngology. $2^{\text {nd }}$ ed. In: Paparella MM, Shumrick DA, editors. Eastbourne: W.B. Saunders; 1980. p. 14.3.5.

4. Somefun OA, Adefuye SA, Danfulani MA, Afolabi S, Okeowo PA. Adult onset otitis media with effusion in Lagos. Niger Postgrad Med ] 2005;12:73-6.

5. Luxford WM, Sheehy]L. Myringotomy and ventilation tubes: A report of 1,568 ears. Laryngoscope 1982;92:1293-7.

6. Van Heerbeek N, de Saar C, Mulder J]. Long term ventilation tubes: Result of 726 insertions. Clin Otolaryngol 2002;27:378-83.

7. Robinson PM. Secretory otitis media in the adults. Clin Otolaryngol 1987;12:297-302.

8. Zikk D, Himelfarb MK, Shanon F. Sudden hearing loss in the elderly. Clin Otolaryngol 1985;10:191-4. 